\title{
PENGARUH MINAT PENGUNJUNG UPTD AGRIBISNIS BUAH NAGA REMBANGAN DI KECAMATAN ARJASA
}

\author{
Ariesia Ayuning Gema Putri ${ }^{1 *}$, Dyah Kusuma Wardhani ${ }^{2}$, Paramita Andini ${ }^{3}$, Ayu Farhana ${ }^{4}$ \\ Department of Agribusiness Management, Politeknik Negeri Jember 68101 \\ Department of Management, Universitas Islam Negeri Kiai Haji Achmad Siddiq Jember 68136 \\ ariesia@polije.ac.id
}

\begin{abstract}
Jember Tourism Office intensified tourist village which aims to attract domestic and non-domestic travelers to visit Jember, One of the tourist area in Jember is Rembangan dragon fruit agribusiness area. This area is one of the few tourist attractions with highly prospective in Jember, But beyond the public is less interested in visiting this region. One effort that can be done to overcome this problem is to analyze the affecting visitor interest factors of rembangan dragon fruit agribusiness UPTD district arjasa district jember using natural logarithm analysis and binary logistic regression analysis. This analysis was able to identify whether the factors that may affect the interests of the visitors studied together and what are the most dominant factors affect the interest of visitors to the region Rembangan dragon fruit agribusiness. The results showed that the variable trip length $\left(\mathrm{X}_{1}\right)$, Monthly Income $\left(\mathrm{X}_{2}\right)$, Age of Visitors $\left(\mathrm{X}_{3}\right)$, Leisure Time a Week $\left(\mathrm{X}_{4}\right)$, and Transportation Costs $\left(\mathrm{X}_{5}\right)$ simultaneously significant effect on visitor interest $(\mathrm{Y})$ in the area of agribusiness Rembangan dragon fruit UPTD, District Jember, and the most dominant variable to interest visitors in the area of agribusiness Rembangan dragon fruit UPTD District Jember is a trip length variable.
\end{abstract}

Keywords: Visitor Interest, Dragon Fruit Agribusiness

\begin{abstract}
Abstrak
Dinas Pariwisata Kabupaten Jember menggiatkan desa wisata yang bertujuan untuk menarik wisatawan domestik dan non domestik untuk mengunjungi Kabupaten Jember, Salah satu kawasan wisata yang ada di Kabupaten Jember adalah kawasan UPTD agribisnis buah naga Rembangan. Kawasan ini merupakan satu dari beberapa tempat wisata di Kabupaten Jember yang sangat prospektif, Namun masyarakat diluar Kabupaten Jember kurang begitu berminat untuk mengunjunginya. Salah satu upaya yang dapat dilakukan untuk mengatasi hal tersebut yaitu dengan menganalisis faktor-faktor yang mempengaruhi minat pengunjung ke kawasan UPTD agribisnis buah naga Rembangan dengan menggunakan analisis logaritma natural dan analisis regresi logistik biner. Analisis ini mampu mengidentifikasi apakah faktor yang diteliti dapat mempengaruhi minat pengunjung secara bersama-sama dan faktor apa yang paling dominan berpengaruh pada minat pengunjung ke kawasan agribisnis buah naga Rembangan. Hasil penelitian menunjukkan bahwa Variabel Lama Perjalanan $\left(X_{1}\right)$, Penghasilan Perbulan $\left(X_{2}\right)$, Usia Pengunjung $\left(X_{3}\right)$, Waktu Luang Perminggu $\left(X_{4}\right)$, dan Biaya Transportasi $\left(X_{5}\right)$ secara serempak berpengaruh signifikan terhadap Minat Pengunjung (Y) di kawasan UPTD agribisnis buah naga Rembangan, Kabupaten Jember, dan Variabel paling dominan terhadap minat pengunjung di kawasan UPTD agribisnis buah naga Rembangan, Kabupaten Jember adalah variabel lama perjalanan
\end{abstract}

Kata kunci: Minat Pengunjung, Agribisnis Buah Naga.
1. Pendahuluan
Obyek wisata yang belum begitu dikenal khalayak umum Dinas Pariwisata Kabupaten Jember sejak tahun 2009 namun sangat berpotensi sebagai salah satu obyek wisata menggiatkan desa wisata yang bertujuan menarik wisatawan yang menarik di kota Jember yaitu obyek wisata Rembangan domestik dan non domestik. Dinas Pariwisata Propinsi Jawa yang terletak di desa Kemuninglor Kecamatan Arjasa Timur, menyebutkan di Kabupaten Jember ada 3 desa yang Kabupaten Jember. Obyek wisata ini merupakan salah satu dikemas diantaranya desa Kemuning Lor Kecamatan Arjasa, tempat peristirahatan yang berhawa sejuk dan segar, desa Sukorambi Kecamatan Sukorambi dan desa Sumberrejo disamping itu juga tersedia sarana akomodasi, restoran, Kecamatan Ambulu. tempat bermain anak dan lainnya yang berada di lahan seluas 
13,45 hektar. Potensi lainnya adalah potensi agribisnis buah 2.3 Variabel

naga yang seharusnya dapat dikemas menjadi paket wisata, dalam hal ini wisatawan dapat memetik buah naga langsung dari pohonnya. ${ }^{[1]}$

Kawasan UPTD agribisnis buah naga Rembangan memiliki ketinggian 650 meter diatas permukaan laut (mdpl) dan terletak di Desa Kemuning Lor, Kecamatan Arjasa, Kabupaten Jember, Jawa Timur. Kawasan ini dikelola oleh 2. Pemkab Jember dan berada sekitar 15 kilometer arah utara Kota Jember. Kebun buah naga yang dikelola Dinas Pertanian Jember itu luasnya mencapai 5 hektar dan tanaman tersebut menggunakan pupuk organik sehingga dapat dipanen dua hingga tiga kali dalam setahun di bulan Desember hingga Mei.

Buah naga di Rembangan merupakan salah satu keunggulan yang dapat dimanfaatkan sebagai salah satu paket wisata yang bisa menarik pengunjung demi meningkatkan pendapatan masyarakat di sekitarnya jika di kelola dengan benar. Lokasi yang strategis serta ditopang dengan pemandangan alam sekitar yang indah seharusnya menjadi sesuatu hal yang bisa menarik minat pengunjung untuk mengunjungi tempat ini. Minat merupakan keadaan mental yang menghasilkan respon terarah kepada sesuatu, situasi atau obyek tertentu yang menyenangkan dan memberikan kepuasan kepadanya. Slameto (2010:180) mendefinisikan, "Minat adalah rasa lebih suka dan rasa ketertarikan pada suatu hal atau aktivitas, tanpa ada yang menyuruh". Dewasa ini, minat masyarakat untuk mengunjungi kawasan agribisnis buah naga di Rembangan semakin menurun, hal ini terlihat dari sepinya lokasi ini setiap harinya. Beberapa faktor yang mempengaruhi minat pengunjung diantaranya adalah Lama Perjalanan, Penghasilan Perbulan, Usia Pengunjung, Waktu luang Perminggu, dan Biaya Transportasi. [2] Belum berkembangnya lokasi ini secara maksimal disebabkan terbatasnya perhatian dan kapasitas SDM lokal dalam menangkap peluang sektor wisata. Potensi yang dimiliki oleh kawasan ini kurang tereksplor dengan maksimal, akibatnya informasi akan keberadaan kawasan ini menjadi sangat minim, sehingga perlu dianalisis faktor apa yang sebenarnya menjadi keinginan atau minat pengunjung untuk mengunjungi kawasan agribisnis buah naga Rembangan.

\section{Metode Penelitian}

\subsection{Desan Penelitian}

Desain penelitian yang digunakan dalam penelitian ini adalah penelitian survey research, Menurut Arikunto (2006), Penelitian survai merupakan penelitian yang mengumpulkan data sebanyak-banyaknya mengenai faktorfaktor yang merupakan pendukung kemudian menganalisis faktor-faktor tersebut dengan menggunakan daftar pertanyaan (kuisioner) sebagai alat pengumpulan terstruktur. Penelitian ini menjelaskan hubungan antar variabel preduktor (independen) terhadap variabel kriterium (dependen). ${ }^{[4]}$

\subsection{Populasi dan Sampel}

Menurut Sedarmayanti (2002:121) populasi adalah himpunan keseluruhan karakteristik dari obyek yang diteliti, hal ini adalah seluruh pengunjung yang datang ke kawasan agribisnis buah naga Rembangan. Sedangkan sampel adalah kelompok kecil yang diamati dan merupakan bagian dari populasi sehingga sifat dan karakteristik populasi juga dimiliki oleh sampel. (Sedarmayanti, 2002:124)
Berdasarkan pokok permasalahan yang diajukan maka variabel-variabel yang dianalisis dapat dikelompokkan menjadi :

Variabel terikat atau dependent (Y) adalah minat pengunjung di kawasan Agribisnis Buah Naga Rembangan Kecamatan Arjasa Kabupaten Jember.

Variabel bebas atau independent (X) yaitu meliputi lama perjalanan, penghasilan perbulan, usia pengunjung, waktu luang perminggu, dan biaya transportasi.

\subsection{Instrumen Penelitian}

Instrumen utama yang digunakan dalam penelitian ini adalah kuesioner yang ditujukan kepada seluruh sampel pengunjung di kawasan agribisnis buah naga Rembangan. Sebelum disebarkan kepada seluruh sampel konsumen sebagai data primer atau responden sebenarnya, kuesioner tersebut diuji terlebih dahulu validitas dan reliabilitasnya. Kuisioner adalah alat penelitian survai yang berisi daftar pertanyaan tertulis, yang bertujuan untuk Te tanggapan dari orang atau kelompok yang terpilih sebagai sampel (Ariestonandri, 2006:71). Data yang diperoleh kemudian diuji dengan menggunakan rumus Ln. ${ }^{[5]}$

\subsection{Lokasi dan Waktu}

Lokasi penelitian ini dilakukan di Kawasan UPTD Agribisnis Buah Naga Kecamatan Arjasa Kabupaten Jember. Jangka waktu pelaksanaan dari penelitian ini adalah selama \pm 5 bulan, dari Bulan Agustus sampai Desember. Penetapan lokasi penelitian dilakukan secara sengaja atas dasar pertimbangan bahwa Kawasan UPTD Agribisnis Buah Naga Kecamatan Arjasa Kabupaten Jember, merupakan kawasan agribisnis yang sangat menarik dan membutuhkan peningkatan minat pengunjung sesuai dengan tujuan Dinas Pariwisata Kabupaten Jember yang ingin menggiatkan desa wisata di Kabupaten Jember, sehingga analisis terhadap faktor-faktor yang mempengaruhi minat pengunjung sangatlah penting.

\subsection{Prosedur Pengumpulan Data}

Tahapan pengumpulan data yang dilakukan dalam penelitian ini adalah sebagai berikut :

1. Tahapan sebelum pengumpulan data di lapang, yaitu mengadakan pengamatan dan penelitian pendahuluan pada Kawasan UPTD Agribisnis Buah Naga Kecamatan Arjasa Kabupaten Jember.

2. Tahapan pengumpulan data primer dengan menggunakan kuisioner yang diperoleh secara langsung dari responden yaitu informasi atau data dari jawaban seluruh karyawan pada Kawasan UPTD Agribisnis Buah Naga Kecamatan Arjasa Kabupaten Jember.

3. Tahapan pengumpulan data sekunder diperoleh dari informasi data yang dimiliki perusahaan, berbagai macam bentuk terbitan oleh media masa ataupun perusahaan penerbit, serta buku literatur yang berkaitan dengan pengaruh minat pengunjung ke Kawasan UPTD 

Agribisnis Buah Naga Kecamatan Arjasa Kabupaten
Jember.

\subsection{Analisis Logaritma Natural}

Logaritma natural adalah logaritma yang berbasis 10, karena basis angka yang digunakan umumnya juga 10 . Terdapat dua alasan mengapa $\operatorname{Ln}(\mathrm{x})$ disebut logaritma natural: pertama, persamaanpersamaan yang variable tak diketahuinya merupakan pangkat dari e jauh lebih sering dijumpai dibanding yang merupakan pangkat dari 10 (karena sifat-sifat "natural" dari fungsi eksponensial yang dapa decay/penurunan), dan kedua, karena logaritma natural dapat didefinisikan dengan mudah menggunakan integral yang dasar atau deret taylor, dan logaritma berbasis lainnya tidak dapat didefinisikan seperti ini.

\subsection{Teknik Analisis}

Banyak dijumpai variabel response $\mathrm{Y}$ yang hanya mempunyai dua kategori, seperti: sukses-gagal, ya-tidak, benar-salah, hidup-mati, hadir-bolos, priaperempuan. Variabel dengan dua kategori ini sering disebut variabel dikotomi (dichotomous variable) atau variabel biner (binary variable). Bila kedua nilai variabel biner ini dilambangkan dengan $1=$ sukses dan $0=$ gagal. Analisis Regresi Logistik Biner digunakan untuk melihat pengaruh sejumlah variabel independen $\mathrm{x}_{1}, \mathrm{x}_{2}, \ldots$ Terhadap variabel dependen y yang berupa variabel response biner yang hanya mempunyai dua nilai atau juga untuk memprediksi nilai suatu variabel dependen y (yang berupa variabel biner) berdasarkan nilai variabel-variabel independen $\mathrm{x}_{1}, \mathrm{x}_{2}, \ldots$ (Uyanto, 2009).

Menurut Uyanto (2009), Bentuk umum model peluang regresi logistik dengan $\mathrm{p}$ variabel penjelas, diformulasikan sebagai berikut:

$$
\pi(x)=\frac{\exp \left(\beta_{0}+\beta_{1} x_{1}+\ldots \ldots+\beta_{p} x_{p}\right)}{1+\exp \left(\beta_{0}+\beta_{1} x_{1}+\ldots \ldots+\beta_{p} x_{p}\right)}
$$

Dengan $\pi(\mathrm{x})$ adalah peluang kejadian sukses dengan nilai probabilitas $0 \leq \pi(\mathrm{x}) \leq 1$ dan $\beta \mathrm{j}$ adalah nilai parameter dengan $j=1,2, \ldots \ldots .$, p. $\pi(x)$ merupakan fungsi yang non linier, sehingga perlu dilakukan transformasi ke dalam bentuk logit untuk memperoleh fungsi yang linier agar dapat dilihat hubungan antara variabel bebas dan variabel tidak bebas. Dengan melakukan transformasi dari logit $\pi(\mathrm{x})$, maka didapat persamaan yang lebih sederhana, yaitu:

$$
g(x)=\ln \frac{\pi(x)}{[1-\pi(x)]}=\left(\beta_{0}+\beta_{1} x_{1}+\ldots \ldots+\beta_{p} x_{p}\right)
$$

Jika dari beberapa variabel bebas ada yang berskala nominal atau ordinal, maka variabel tersebut tidak akan tepat jika dimasukkan dalam model logit karena angka-angka yang digunakan untuk menyatakan tingkatan tersebut hanya sebagai identifikasi dan tidak mempunyai nilai numerik dalam situasi seperti ini diperlukan variabel dummy. Untuk variabel bebas dengan skala ordinal maupun nominal dengan $\mathrm{k}$ kategori, akan diperlukan sebanyak k-1 variabel dummy. ${ }^{[6]}$

\section{Hasil dan Pembahasan}

3.1 Hasil Logaritma Natural (Ln)

Kuesioner disebar kepada 40 responden atau pengunjung kawasan UPTD Agribisnis Buah Naga Rembangan Kecamatan Arjasa Kabupaten Jember, kemudian hasil dari 40 responden tersebut akan di olah kembali dengan menggunakan Logarima Natural (Ln), hal ini bertujuan untuk menyeragamkan data yang didapat dari hasil kuisioner. Hal ini disebabkan karena data yang diperoleh dari hasil kuisioner tidak beraturan dan tidak seragam sehingga tidak dapat langsung diolah dengan analisis regresi logistik biner.

\subsection{Hasil Analisis Regresi Logistik Biner}

Analisis penelitian yang dilakukan pada 40 responden di kawasan UPTD Agribisnis Buah Naga Rembangan Kecamatan Arjasa Kabupaten Jember akan mampu menjelaskan pengaruh variabel bebas terhadap variabel terikat setelah diolah dengan menggunakan logaritma natural (Ln) terlebih dahulu. Faktor-faktor yang diidentifikasi sebagai variabel dalam penelitian ini yaitu variabel terikat adalah Minat Pengunjung (Y), dan variabel bebas adalah Lama Perjalanan $\left(\mathrm{X}_{1}\right)$, Penghasilan Perbulan $\left(\mathrm{X}_{2}\right)$, Usia Pengunjung $\left(\mathrm{X}_{3}\right)$, Waktu Luang Perminggu $\left(\mathrm{X}_{4}\right)$, dan Biaya Transportasi $\left(\mathrm{X}_{5}\right)$.

Tabel 1. Jumlah Sampel yang dimasukkan dalam Regresi Logistik Biner

\begin{tabular}{|c|c|c|c|}
\hline \multicolumn{2}{|c|}{ Unweighted Cases $^{a}$} & $\mathrm{~N}$ & Percent \\
\hline Selected & Included in Analysis & 40 & 100.0 \\
\hline & Missing Cases & 0 & .0 \\
\hline & Total & 40 & 100.0 \\
\hline Unselectec & Cases & 0 & .0 \\
\hline Total & & 40 & 100.0 \\
\hline
\end{tabular}

Case Processing Summary

Jumlah Sampel Yang Dimasukkan Dalam Regresi Logistik Biner Untuk Dianalisa, menunjukkan tidak adanya missing cases, artinya data yang diproses lengkap. Hal ini menunjukkan bahwa terdapat 40 sampel yang memenuhi kriteria untuk diteliti pada penelitian ini, sehingga menjadi selaras dengan jumlah responden riil yang diteliti sebesar 40 responden, dan dapat disimpulkan 40 orang responden yang diteliti semuanya memenuhi syarat untuk dilakukannya penelitian.

Tabel. 2. Pengkodean Variabel Dependen

Dependent Variable Encoding

\begin{tabular}{|l|r|}
\hline \multicolumn{1}{|c|}{ Original Value } & Internal Value \\
\hline Tidak Berminat & 0 \\
Berminat & 1 \\
\hline
\end{tabular}


16,264 dengan derajat kebebasan $=5$. P-value $=0,006$ lebih

Pengkodean Variabel Dependen, menunjukkan hasil kecil dari $\alpha=0,05$ sehingga hasil uji ini sangat signifikan. input data yang digunakan pada variabel dependen minat Sehingga dapat dikatakan bahwa secara bersama-sama pengunjung diberi kode $0=$ tidak berminat dan $1=$ berminat. variabel Lama Perjalanan $\left(\mathrm{X}_{1}\right)$, Penghasilan Perbulan $\left(\mathrm{X}_{2}\right)$, Model regresi logistik biner digunakan pada penelitian ini Usia Pengunjung $\left(\mathrm{X}_{3}\right)$, Waktu Luang Perminggu $\left(\mathrm{X}_{4}\right)$, dan karena variabel dependen bersifat dikotomi, yaitu ingin Biaya Transportasi $\left(\mathrm{X}_{5}\right)$ secara bersama-sama berpengaruh mengetahui minat pengunjung apakah berminat berkunjung signifikan terhadap Minat Pengunjung (Y) ke kawasan UPTD lagi ke kawasan UPTD agribisnis buah naga Rembangan, agribisnis buah naga Rembangan.

dimana hanya ada dua penilaian, yaitu berminat atau tidak Tabel 6 Hasil Pengujian Hipotesis Secara Parsial berminat.

Tabel 3. Tingkat Keakuratan dengan Memasukkan Seluruh Variabel Independen

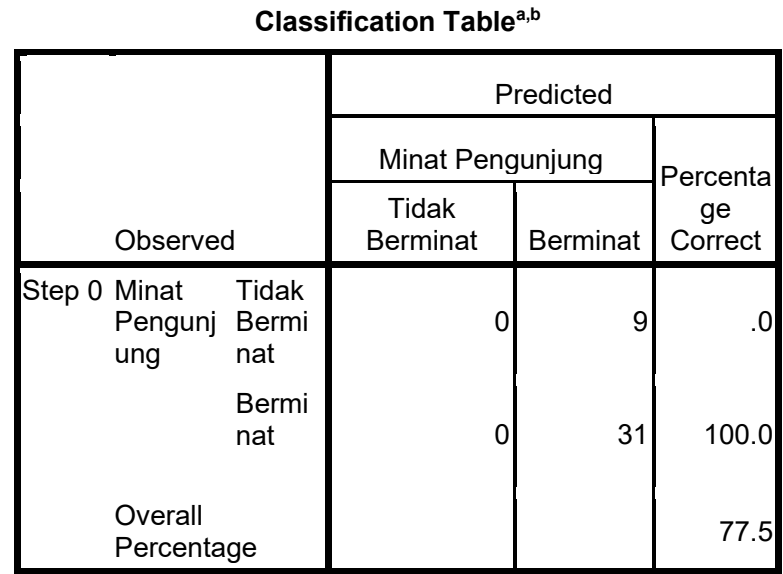

Tabel 3. Classification Table menunjukkan tabel $2 \times 2$ dengan kolom berupa predicted values dari variabel dependen dan baris berupa nilai data aktual yang diamati. Untuk model yang sempurna, semua cases akan terletak pada diagonal tabel dan Overall Percentage akan bernilai $100 \%$. Overall Percentage yang memprediksi model dengan benar mempunyai nilai cukup baik sebesar $77,5 \%$ dan menunjukkan bahwa model yang telah memasukkan konstanta dan variabel independen lebih baik.

Tabel 4. Variabel In The Equation

Variables in the Equation

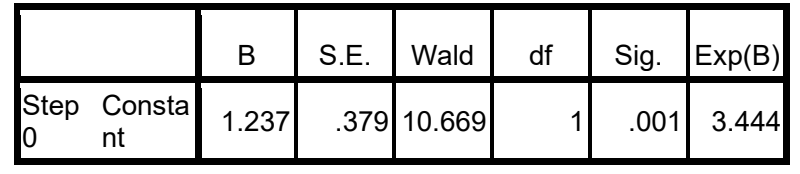

Uji Wald pada Tabel 4 Variables in the Equation digunakan untuk menguji apakah masing-masing koefisien regresi logistik signifikan. Dalam contoh ini uji wald $=$ 10,669. P-value $=0,001$ lebih kecil dari $\alpha=0,05$. Kesimpulan Constant dari model regresi logistik ini signifikan. ${ }^{[7]}$

Tabel 5. Hasil Pengujian Hipotesis Secara Bersama-sama

Omnibus Tests of Model Coefficients

\begin{tabular}{|c|c|c|c|c|}
\hline & & Chi-square & $\mathrm{df}$ & Sig. \\
\hline \multirow{3}{*}{$\begin{array}{l}\text { Step } \\
1\end{array}$} & Step & 16.264 & 5 & .006 \\
\hline & Block & 16.264 & 5 & .006 \\
\hline & Model & 16.264 & 5 & .006 \\
\hline
\end{tabular}

Tabel 5. Omnibus Test of Model Coefficients memberikan nilai chi-square goodness-of-fit test sebesar yang dilakukan oleh Prihatin (2010). 
Variabel bebas penghasilan perbulan $\left(\mathrm{X}_{2}\right)$ mempunyai $p$ value $=0,99$ lebih besar dari $\alpha=0,05$, maka koefisien regresi untuk variabel penghasilan perbulan tidak berpengaruh signifikan terhadap minat pengunjung ke kawasan UPTD agribisnis buah naga Rembangan. Hasil tersebut tidak konsisten dengan penelitian sebelumnya yang dilakukan oleh Prihatin (2010).

Variabel bebas usia pengunjung $\left(\mathrm{X}_{3}\right)$ mempunyai $p$ value $=0,64$ lebih besar dari $\alpha=0,05$, maka koefisien regresi untuk variabel usia pengunjung tidak berpengaruh signifikan terhadap minat pengunjung ke kawasan UPTD agribisnis buah naga Rembangan. Hasil tersebut konsisten dengan penelitian sebelumnya yang dilakukan oleh Syahadat (2009). Peneliti sebelumnya menyatakan bahwa secara parsial variabel usia pengunjung $\left(\mathrm{X}_{3}\right)$ memiliki pengaruh yang tidak signifikan terhadap minat pengunjung.

Variabel bebas waktu luang perminggu $\left(\mathrm{X}_{4}\right)$ mempunyai $p$-value $=0,45$ lebih besar dari $\alpha=0,05$, maka koefisien regresi untuk variabel waktu luang perminggu tidak berpengaruh signifikan terhadap minat pengunjung ke kawasan UPTD agribisnis buah naga Rembangan, maka hipotesis ditolak. Hasil tersebut konsisten dengan penelitian sebelumnya yang dilakukan oleh Prihatin (2010). Peneliti sebelumnya menyatakan bahwa secara parsial variabel waktu luang perminggu $\left(\mathrm{X}_{4}\right)$ memiliki pengaruh yang tidak signifikan terhadap minat pengunjung

Variabel bebas biaya transportasi $\left(\mathrm{X}_{5}\right)$ mempunyai $p$ value $=0,90$ lebih besar dari $\alpha=0,05$, maka koefisien regresi untuk variabel biaya transportasi tidak berpengaruh signifikan terhadap minat pengunjung ke kawasan UPTD agribisnis buah naga Rembangan, maka hipotesis ditolak. Hasil tersebut konsisten dengan penelitian sebelumnya yang dilakukan oleh Prihatin (2010). Peneliti sebelumnya menyatakan bahwa secara parsial variabel biaya transportasi (Xs) memiliki pengaruh yang tidak signifikan terhadap minat pengunjung

Berdasarkan hasil analisis data yang telah dilaksanakan, maka Lama Perjalanan $\left(\mathrm{X}_{1}\right)$, Penghasilan Perbulan $\left(\mathrm{X}_{2}\right)$, Usia Pengunjung $\left(\mathrm{X}_{3}\right)$, Waktu Luang Perminggu $\left(\mathrm{X}_{4}\right)$, dan Biaya Transportasi $\left(\mathrm{X}_{5}\right)$ secara serempak berpengaruh signifikan terhadap Minat Pengunjung (Y) di kawasan UPTD agribisnis buah naga Rembangan, Kabupaten Jember. Hal ini ditunjukkan pada Tabel 5.10 Hasil Pengujian Hipotesis Secara Bersama-sama memberikan nilai chi-square goodness-of-fit test sebesar 16,264 dengan derajat kebebasan $=5$. P-value $=0,006$ lebih kecil dari $\alpha=0,05$ sehingga hasil uji ini sangat signifikan. Hasil penelitian ini konsisten dengan penelitian sebelumnya yang dilakukan Prihatin (2010) yang menyatakan bahwa faktor-faktor yang mempengaruhi kunjungan ke ekowisata Taman Nasional Gunung Halimun pada taraf uji 5\% adalah jarak tempat tinggal, lama perjalanan, kesediaan membayar, hari kunjungan, penghasilan perbulan dan jumlah rekreasi pengunjung dalam satu tahun terakhir. Serta penelitian yang dilakukan oleh Syahadat (2009) yang menyatakan bahwa faktor usia pengunjung, faktor sarana prasarana, faktor obyek dan daya tarik wisata alam, dan faktor keamanan secara bersama-sama (simultan) mempunyai pengaruh terhadap jumlah pengunjung akan tetapi tidak secara nyata (tidak signifikan) di Taman Nasional Gede Pangrango

Berdasarkan hasil analisis data yang telah dilaksanakan, dapat dilihat adanya bukti bahwa pengaruh paling dominan terhadap minat pengunjung di kawasan UPTD agribisnis buah naga Rembangan, Kabupaten Jember adalah variabel lama perjalanan dengan $p$-value $=0,04$ lebih kecil dari $\alpha=0,05$. Nilai analisis tersebut menunjukkan bahwa minat pengunjung dipengaruhi oleh atribut lama perjalanan pengunjung ke kawasan UPTD agribisnis buah naga rembangan. Hasil penelitian ini sesuai dengan penelitian sebelumnya yang dilakukan oleh Prihatin (2010). Peneliti sebelumnya menyatakan bahwa secara parsial variabel lama perjalanan memiliki pengaruh yang signifikan terhadap minat pengunjung ke suatu tempat.

\section{Kesimpulan}

Berdasarkan hasil analisis dan pembahasan faktorfaktor yang mempengaruhi minat pengunjung ke kawasan UPTD agribisnis buah naga rembangan, maka dapat ditarik kesimpulan sebagai berikut :

1. Variabel lama perjalanan $\left(\mathrm{X}_{1}\right)$ berpengaruh secara signifikan terhadap minat pengunjung (Y) ke UPTD agribisnis buah naga Rembangan Kecamatan Arjasa, Kabupaten Jember.

2. Variabel penghasilan perbulan $\left(\mathrm{X}_{2}\right)$ berpengaruh secara tidak signifikan terhadap minat pengunjung (Y) ke UPTD agribisnis buah naga Rembangan Kecamatan Arjasa, Kabupaten Jember.

3. Variabel usia pengunjung $\left(\mathrm{X}_{3}\right)$ berpengaruh secara tidak signifikan terhadap minat pengunjung (Y) ke UPTD agribisnis buah naga Rembangan Kecamatan Arjasa, Kabupaten Jember.

4. Variabel waktu luang perminggu $\left(\mathrm{X}_{4}\right)$ berpengaruh secara tidak signifikan terhadap minat pengunjung (Y) ke UPTD agribisnis buah naga Rembangan Kecamatan Arjasa, Kabupaten Jember.

5. Variabel biaya transportasi $\left(\mathrm{X}_{5}\right)$ berpengaruh secara tidak signifikan terhadap minat pengunjung (Y) ke UPTD agribisnis buah naga Rembangan Kecamatan Arjasa, Kabupaten Jember

6. Berdasarkan hasil analisis data yang telah dilaksanakan, maka Lama Perjalanan $\left(\mathrm{X}_{1}\right)$, Penghasilan Perbulan $\left(\mathrm{X}_{2}\right)$, Usia Pengunjung $\left(\mathrm{X}_{3}\right)$, Waktu Luang Perminggu $\left(\mathrm{X}_{4}\right)$, dan Biaya Transportasi $\left(\mathrm{X}_{5}\right)$ secara serempak berpengaruh signifikan terhadap Minat Pengunjung (Y) di kawasan UPTD agribisnis buah naga Rembangan, Kabupaten Jember.

7. Berdasarkan hasil analisis data yang telah dilaksanakan, dapat dilihat adanya bukti bahwa pengaruh paling dominan terhadap minat pengunjung di kawasan UPTD agribisnis buah naga Rembangan, Kabupaten Jember adalah variabel lama perjalanan dengan $p$-value $=0,04$ lebih kecil dari $\alpha=0,05$.

\subsection{Saran}

Berdasarkan hasil pembahasan dan kesimpulan dapat diberikan saran sebagai berikut:

1. Lama perjalanan untuk berkunjung ke UPTD Agribisnis Buah Naga Rembangan Kecamatan Arjasa Kabupaten Jember sudah merupakan faktor yang paling dominan oleh sebab itu agar lokasi UPTD Agribisnis Buah Naga Rembangan Kecamatan Arjasa Kabupaten Jember tetap menjadi tujuan utama untuk berkunjung, pihak manajemen harus membenahi fasilitas-fasilitas umum seperti jalan raya, suasana perjalanan yang menarik, dan sebagainya, sehingga pengunjung dari dalam maupun luar daerah Kabupaten Jember merasa puas dengan keadaan yang ada, dengan kepuasan dalam kunjungannya maka minat kunjungan pun dapat meningkat.

2. Selain kelima variabel independen dalam penelitian ini, yaitu Lama Perjalanan, Penghasilan Perbulan, Usia 
Pengunjung, Waktu Luang Perminggu, dan Biaya Transportasi masih banyak faktor lain yang juga mempengaruhi minat pengunjung dalam mengunjungi suatu lokasi. Oleh karena itu, penulis menyarankan kepada peneliti lain yang akan meneliti permasalahan yang sama, tentang minat pengunjung agar menggunakan dan atau menambah variabel yang lain.

\section{Daftar Rujukan}

[1] Dumadezirer. 2009. Mengisi Waktu Luang Yang Produktif. Jakarta: Pradnya Paramita

[2] Kunarso, Adi. 2008. Pengaruh Perilaku Pengunjung terhadap Jumlah Kunjungan di Taman Wisata Alam Punti Kayu Palembang. Jurnal Ilmu Manajemen Akuntansi dan Terapan STIE Totalwin Semarang. http://e-journal.stie-totalwin.ac.id/ejournal/index.php/excellent. diakses pada tanggal 08 Agustus 2013

[3] Abadi, Jesslyn. 2009. Faktor-Faktor yang Mempengaruhi Minat Pengunjung terhadap Kolam Renang Air Asin Hotel Tirta Mandala di Jayapura-Papua. Jurnal Ilmu Manajemen Akuntansi dan Terapan STIE Totalwin Semarang. $\quad$ http://e-journal.stie-totalwin.ac.id/ejournal/index.php/excellent. diakses pada tanggal 08 Agustus 2013.

[4] Prihatin, Sinta. 2010. Pengelolaan Ekowisata Taman Nasional Gunung Halimun dan Faktor-Faktor yang Mempengaruhi Kunjungannya. Jurnal Ilmu Sosial Ekonomi Pertanian Fakultas Pertanian Institut Pertanian Bogor. $\quad$ http://e-journal.ipb.ac.id/ejournal/index.php/excellent. diakses pada tanggal 08 Agustus 2013

[5] Slameto. 2010. Belajar dan Faktor - Faktor yang Mempengaruhinya. Jakarta: Rinelka Cipta

[6] Syahadat, Epi. 2009. Faktor - Faktor Yang Mempengaruhi Kunjungan Wisatawan Di Taman Nasional Gede Pangrango (TNGP). Jurnal Ilmu Manajemen Akuntansi dan Terapan STIE Totalwin Semarang. $\quad$ http://e-journal.stie-totalwin.ac.id/ejournal/index.php/excellent. diakses pada tanggal 08 Agustus 2013.

[7] Gozali, Imam. 2005. Analisis Mulitivariate Dengan Progam SPSS. Semarang: Undip. 